\title{
O DIREITO À COMUNICAÇÃo NO PLENÁRIO DA ASSEMBLEIA NACIONAL CONSTITUINTE
}

\author{
THE RIGHT TO COMMUNICATION IN THE PLENARY OF THE NATIONAL \\ CONSTITUENT ASSEMBLY
}

\author{
EL DERECHO A LA COMUNICACIÓN EN EL PLENARIO \\ DE LA ASAMBLEA NACIONAL CONSTITUYENTE
}

\author{
Carlo José napolitano \\ Doutor, Faculdade de Arquitetura, Artes e \\ Comunicação - Unesp \\ carlonapolitano@faac.unesp.br
}

\begin{abstract}
RESUMO
O presente trabalho trata-se de um relato parcial de pesquisa em andamento que pretende verificar a regulação do direito à comunicação, elaborado durante o processo constituinte de $87 / 88$. Por hipótese, a pesquisa considera que a intenção constituinte era de regular os direitos relacionados à comunicação. Para cumprir esses objetivos a pesquisa analisa as propostas e os debates legislativos durante o processo constituinte, relativos à regulação do direito à comunicação. Neste trabalho especificamente serão apresentados os resultados da pesquisa nos debates parlamentares que ocorreram no plenário da Assembleia Nacional Constituinte. Os resultados parciais da pesquisa apontam que a constituinte pretendeu impor um controle social ao direito à comunicação, corroborando deste modo esta hipótese da pesquisa.
\end{abstract}

PALAVRAS-CHAVE: direito à comunicação; processo constituinte; regulação jurídica.

\begin{abstract}
This text is part of ongoing research that aims to verify the constitutional regulation of the communication rights, elaborated by constituent process on $87 / 88$. For hypothesis, the research considers that was the intention of the constituent regulate the rights related to the communication. To fulfill to these objectives the research analyzes the legislative proposals and debates during the constituent process, related to the regulation of communication rights. In this text specifically will be presented the results of the research the parliamentary debates that had occurred in the plenary of the National Constituent Assembly. The partial results of the research point that the constituent intended to impose a social control to the communication rights, corroborating in this way this hypothesis of the research.
\end{abstract}

KEY WORDS: communication rights; constituent process; legal regulation.

\section{RESUMEN}

El presente trabajo es un informe parcial de la investigación en curso que tiene como objetivo examinar la regulación del derecho a la comunicación, redactado durante el proceso constitucional de 87/88. Por hipótesis, la investigación concluye que la intención era la de regular los derechos constitucionales relacionados con la comunicación. Para cumplir con estos objetivos, la investigación examina las propuestas y los debates legislativos durante el proceso constitucional, relativo a la regulación del derecho a la comunicación. Este trabajo será presentado especificamente los resultados de búsqueda en los debates parlamentarios que se produjeron en el plenario de la Asamblea Nacional Constituyente. Los resultados parciales de la investigación muestran que la constituyente tratado de imponer el control social sobre el derecho a la comunicación, lo que corrobora la hipótesis de la investigación.

PALABRAS CLAVE: derecho a la comunicación; proceso constitucional; regulación legal. 


\section{INTRODUÇÃO ${ }^{1}$}

Trata-se o presente de relato parcial de pesquisa ${ }^{2}$ em andamento que visa investigar a regulação jurídica constitucional do direito à comunicação ${ }^{3}$ e para tanto propõe a revisitação ao processo constituinte no intuito de verificar e interpretar, em uma perspectiva histórica dogmática, a regulação jurídica almejada durante o processo constituinte para o direito à comunicação. Além disso, pretende analisar e interpretar, na mesma perspectiva, a concretização / efetivação desses direitos pelo Supremo Tribunal Federal, comparando a intenção constituinte com a concretização judicial.

Parte a pesquisa de alguns pressupostos: que a atual constituição brasileira, de 05 de outubro de 1988, tem caráter substancial, programática, dirigente, tendo em vista que ela estipula inúmeras finalidades, objetivos e valores que o Estado e a sociedade brasileira devem concretizar ou pelo menos almejar. Sendo um desses valores substantivos almejados no processo constituinte à proteção e a concretização dos direitos fundamentais; que o direito à comunicação, com a constituição de 88 , ganhou status de direito fundamental ${ }^{4}$ e assim deve ser compreendido, aplicando-se a teoria dos direitos fundamentais na interpretação e aplicação desse direito e, por fim, que a constituição de 88 atribui ao judiciário o papel de garantidor dos direitos fundamentais.

\footnotetext{
${ }^{1}$ Uma primeira versão do presente artigo foi apresentado no XXI Congresso Nacional do Conselho Nacional de Pesquisa e Pós-Graduação em Direito (CONPEDI), em novembro de 2012.

${ }^{2}$ A pesquisa intitulada "Direito fundamental à comunicação: regulação jurídica constitucional e concretização pelo Supremo Tribunal Federal" conta com auxílio financeiro da FAPESP (Fundação de Amparo à Pesquisa do Estado de São Paulo), processo n. 2011/00745-0.

${ }^{3}$ A pesquisa considera que o direito à comunicação é composto por um conjunto de direitos isolados, relacionados à regulação jurídica da comunicação, que reunidos se transformam naquele. Dentro desses direitos que compreendem o direito fundamental à comunicação podem ser relacionados: o direito à liberdade de expressão, a regulamentação quanto à pluralidade e diversidade nos meios de comunicação, o direito de antena, a regulamentação dos meios de comunicação social e comunitária, a propriedade dos meios, a liberdade de imprensa, o direito de informação, o direito à informação, a liberdade de opinião, os direitos relacionados à propriedade imaterial, dentre outros, conforme Brant e Kameoka (2005).

${ }^{4}$ A teoria dos direitos fundamentais enfoca o mesmo tema com expressões diversas, tais como, direitos fundamentais, direitos do homem, direitos humanos, direitos subjetivos públicos, liberdades públicas, direitos individuais, liberdades fundamentais, além de outras tantas. A expressão "direitos fundamentais" é tida como a mais adequada, pela teoria jurídica brasileira, pois foi a adotada no texto da constituição federal. A título de observação Bonavides (2000) menciona que a expressão "direitos humanos" é mais utilizada entre os autores anglo-americanos e latinos, enquanto a expressão "direitos fundamentais" é mais utilizada pelos teóricos alemães. Já para Schäfer (2001), direitos fundamentais são aqueles reconhecidos e previstos nas constituições, enquanto os direitos humanos são aqueles previstos nos documentos de direito internacional, como os casos dos tratados internacionais sobre direitos humanos. Na presente pesquisa a terminologia utilizada será "direitos fundamentais".
} 
A pesquisa que se apresenta visa, então, dois objetivos: investigar a regulação constitucional do direito fundamental à comunicação e para tanto revisita o processo constituinte no intuito de verificar e interpretar, em uma perspectiva histórica dogmática, a regulação constitucional do direito fundamental à comunicação elaborado durante o processo constituinte de 87/88 e analisa e interpreta, também em uma visão histórica dogmática, a concretização / efetivação desses direitos pelo Supremo Tribunal Federal, para, por fim, compará-las.

Para tanto, analisa as propostas e os debates legislativos travados durante o processo constituinte de 87/88, relativos à regulação do direito à comunicação. Essa parte da investigação é realizada nos Diários do Congresso Nacional, disponíveis on line e em CD (compact disc), organizados, em 2008, pela Secretaria Especial de Editoração e Publicação do Congresso Nacional, e que contém na íntegra os debates constituintes. Concomitante a essa investigação, estão sendo analisados julgados do Supremo Tribunal Federal, em ações constitucionais $^{5}$, que tem por objeto temas relacionados ao direito à comunicação. A investigação jurisprudencial é realizada no site do Supremo Tribunal Federal ${ }^{6}$.

Por hipótese, a pesquisa partiu do pressuposto que a intenção constituinte foi a de regular $^{7}$ alguns direitos relacionados ao direito à comunicação ${ }^{8}$, em especial, aqueles relacionados à comunicação social, e que ao analisar casos referentes à temática, o Supremo, sistematicamente, vem ampliando a aplicação desses direitos ${ }^{9}$, extirpando qualquer

\footnotetext{
5 Por ações constitucionais entende-se as ações diretas de inconstitucionalidade, ações declaratórias de constitucionalidade, arguições de descumprimento de preceitos fundamentais; recursos extraordinários. Como exemplos de ações constitucionais relacionadas ao direito à comunicação podem ser mencionadas: a ADPF 130 que tratou da lei de imprensa; o Rex 511.961 que analisou a necessidade de diploma em curso superior para o exercício da profissão de jornalista; Reclamação n. 9.428 que tratou da liberdade de imprensa envolvendo o jornal O Estado de São Paulo e Fernando José Macieira Sarney; as Adins n. 3987 e 4077 que tratavam do direito à informação; dentre inúmeras outras.

${ }^{6}$ No portal do Supremo Tribunal Federal há um sofisticado sistema de pesquisa de jurisprudência através de palavras-chave http://www.stf.jus.br/portal/jurisprudencia/pesquisarJurisprudencia.asp. Utilizamos desse recurso quando da elaboração da pesquisa para a tese de doutoramento.

${ }^{7} \mathrm{O}$ termo regulação está sendo usado no presente trabalho no sentido de regulação normativa que compreende, segundo Aguillar (2006), a regulamentação legal e as atividades acessórias de fiscalização e imposição de sanções para as condutas ilícitas. Regular, em outras palavras, seria definir direitos e deveres, delimitar o exercício de direitos, clarificar as suas condições de uso, defender a sociedade e o indivíduo contra eventuais maus usos dos direitos (GONÇALVES, 2003, p. 7).

${ }^{8}$ Essas restrições podem ser verificadas nos seguintes comandos constitucionais: artigo $5^{\circ}$, IV; V; XIII; XIV; XXXIII; artigo 93, IX e artigo 220, especialmente, nos parágrafos $3^{\circ}$ e $4^{\circ}$.

${ }^{9}$ Alguns julgados, como a ADPF 130 e o Rex 511.961 já foram analisados e os resultados divulgados em eventos científicos e em publicações científicas.
} 
possibilidade de regulação da interpretação e consequente aplicação das normas constitucionais.

Neste texto serão apresentados os resultados da pesquisa realizada nos Diários da Constituinte, especificamente, os debates parlamentares que ocorreram em plenário na Assembleia Nacional Constituinte e para tanto está assim estruturado: apresentação de um breve resumo do processo decisório da $\mathrm{ANC}$, metodologia da pesquisa, resultados dos achados no plenário da ANC e conclusões.

\section{BREVE RESUMO DO PROCESSO DECISÓRIO DA ASSEMBLEIA NACIONAL CONSTITUINTE}

A Assembleia Nacional Constituinte foi instalada em 02 de fevereiro de 1987 e terminou em 05 de outubro de 1988, com a promulgação da nova constituição.

No intuito de racionalização dos trabalhos os 559 deputados e senadores constituintes foram subdivididos em 34 foros decisórios, sendo que a elaboração do novo texto constitucional "devia começar pelas 24 subcomissões temáticas, que entregariam seus anteprojetos a 8 comissões temáticas e estas, seus anteprojetos à Comissão de Sistematização, que por sua vez entregaria ao Plenário da ANC o Projeto de Constituição" (PILATTI, 2008, p. $57)^{10}$.

${ }^{10}$ I) COMISSÃO DA SOBERANIA E DOS DIREITOS E GARANTIAS DO HOMEM E DA MULHER: I-A) Subcomissão da Nacionalidade, da Soberania e das Relações Internacionais; I-B) Subcomissão dos Direitos e Garantias Individuais; I-C) Subcomissão dos Direitos Políticos, dos Direitos Coletivos e Garantias. II) COMISSÃO DA ORGANIZAÇÃO DO ESTADO: II-A) Subcomissão da União, Distrito Federal e Territórios; II-B) Subcomissão dos Estados; II-C) Subcomissão dos Municípios e Regiões. III) COMISSÃO DA ORGANIZAÇÃO DOS PODERES E SISTEMA DE GOVERNO: III-A) Subcomissão do Poder Legislativo; IIIB) Subcomissão do Poder Executivo; III-C) Subcomissão do Poder Judiciário e do Ministério Público. IV) COMISSÃO DA ORGANIZAÇÃO ELEITORAL, PARTIDÁRIA E GARANTIA DAS INSTITUIÇÕES: IV-A) Subcomissão do Sistema Eleitoral e Partidos Políticos; IV-B) Subcomissão da Defesa do Estado, da Sociedade e de sua Segurança; IV-C) Subcomissão de Garantia da Instituição, Reformas e Emendas. V) COMISSÃO DO SISTEMA TRIBUTÁRIO, ORÇAMENTO E FINANÇAS: V-A) Subcomissão de Tributos, Participação e Distribuição de Receitas; V-B) Subcomissão de Orçamentos e Fiscalização Financeira; V-C) Subcomissão do Sistema Financeiro. VI) COMISSÃO DA ORDEM ECONÔMICA: VI-A) Subcomissão Princípios Gerais, Intervenção do Estado, Regime da Propriedade do Subsolo e Atividade Econômica; VI-B) Subcomissão da Questão Urbana e Transporte; VI-C) Subcomissão da Política Agrícola e Fundiária e da Reforma Agrária. VII) COMISSÃO DA ORDEM SOCIAL: VII-A) Subcomissão dos Direitos dos Trabalhadores e Servidores Públicos; VII-B) Subcomissão de Saúde, Seguridade e do Meio Ambiente; VII-C) Subcomissão dos Negros, Populações Indígenas, Pessoas Deficientes e Minorias. VIII) COMISSÃO DA FAMÍLIA, DA EDUCAÇÃO, CULTURA E ESPORTES, DA CIÊNCIA E TECNOLOGIA E DA COMUNICAÇÃO: VIII-A) Subcomissão da Educação, 
Em trabalho pioneiro sobre a constituinte, Pilatti (2008, p. 5) relatou que "a grande dificuldade de escrever uma 'história da Constituinte de 1987-88' reside justamente na gigantesca dimensão daquele processo decisório, seja no que se refere à temporalidade (quatro fases, além da preliminar, todas percorridas em 20 meses), seja no que se refere ao espaço decisório (34 foros)".

Ainda segundo Pilatti (2008, p. 52), devido a essa divisão de trabalhos, a sociedade brasileira presenciou uma extensa "agenda constitucional".

Verificou-se, também, que a divisão inicial dos trabalhos constituintes reflete, com algumas poucas alterações, o resultado final do processo constituinte. Como exemplo, a comunicação social foi alocada na oitava comissão que tinha por objeto tratar das questões relacionadas à família, à educação, à cultura e esportes, à ciência e tecnologia e à comunicação. Na divisão das subcomissões a comunicação social foi alocada juntamente com a ciência e tecnologia na subcomissão $8 \mathrm{~B}$. A redação final da constituição alocou a comunicação social no Título VIII (Da Ordem Social), havendo, desta forma, a fusão das comissões temáticas de número 8 e 7 , esta última tratava especificamente das questões relacionadas à ordem social, como os direitos dos trabalhadores, dos servidores públicos, da saúde, seguridade e meio ambiente, negros, populações indígenas, pessoas deficientes e minorias. Como dito, de maneira geral, a estrutura dos trabalhos da constituinte, desde o início, reflete a redação final do texto constitucional. Algumas exceções podem ser apontadas como a transposição dos direitos trabalhistas para o Título II, que trata dos direitos e garantias fundamentais e a transferência dos direitos dos servidores públicos para o Título III, que dispõe sobre a organização do Estado.

Os trabalhos das subcomissões efetivamente tiveram início em 07 de abril de 1987 e terminaram em 22 de maio de 1987. As comissões iniciaram as atividades em 25 de maio, finalizando em 15 de junho de 1987. A comissão de sistematização vigorou de 26 de junho a 18 de novembro 1987, enquanto o plenário esteve reunido de 27 de janeiro a 22 de setembro de 1988 (primeiro e segundo turnos de votação e votação da redação final), quando "o conjunto dos 559 constituintes reassumiu o papel antes delegado às Subcomissões, Comissões

Cultura e Esportes; VIII-B) Subcomissão da Ciência e Tecnologia e da Comunicação; VIII-C) Subcomissão da Família, do Menor e do Idoso. COMISSÃO DE SISTEMATIZAÇÃO. PLENÁRIO. No trabalho de Pilatti (2008) há a indicação dessa divisão, inclusive com os nomes dos constituintes que integravam cada uma delas. 
Temáticas e à Comissão de Sistematização nas sucessivas fases anteriores.” (PILATTI, 2008, p. 229).

Observe-se, no entanto, que o plenário do Congresso Nacional também funcionou durante todo o processo constituinte e relata-se que durante a $\mathrm{ANC}$, somente no plenário, foram realizadas 341 sessões dedicadas a discussões sobre os temas constitucionais, os trabalhos nas Subcomissões e as questões de política ordinária.

\section{METODOLOGIA DAS PESQUISAS NO PLENÁRIO DA ASSEMBLEIA NACIONAL CONSTITUINTE}

Inicialmente pensou-se, tendo em vista a imensidão ${ }^{11}$ das informações contidas nos DCN, a realização da pesquisa através de buscas por palavras-chave relacionadas à temática da investigação, buscando-se as seguintes expressões: "comunicação social"; "meios de comunicação"; "liberdade de imprensa"; "direito à informação"; "oligopólio dos meios"; “monopólio dos meios", para posterior leitura dos achados.

Com a seleção quantitativa separou-se os relatos, debates e proposições relacionados à temática, efetivando-se a leitura dos mesmos.

Os achados nos diários serão transcritos a seguir, em ordem cronológica, mencionando-se qual o constituinte que proferiu o discurso, o partido e estado de origem, os argumentos do parlamentar, no intuito de verificar a sua linha ideológica. Na sequência serão traçados breves comentários sobre a manifestação do constituinte em sede de conclusões.

\section{RESUltados das PESQUiSAS NO PLENÁRIO DA ASSEMBLEIA NACIONAL CONSTITUINTE}

Quantitativamente a pesquisa nas atas das reuniões do plenário chegou aos seguintes resultados: 124 aparições da expressão comunicação social, 421 para meios de comunicação, 56 para liberdade de imprensa, 14 para direito à informação, 3 para oligopólio dos meios e

\footnotetext{
${ }^{11}$ Para se ter uma ideia da dimensão dos dados a Assembleia Nacional Constituinte foi instalada em 02 de fevereiro de 1987 e terminou em 05 de outubro de 1988, com a promulgação da nova constituição. Nesse período (um ano, oito meses e três dias), foram realizadas 341 sessões plenárias. Para cada sessão há um diário com o registro de todas as falas e proposições.
} 
nenhuma para monopólio dos meios.

Verificou-se que desde o início dos trabalhos constituintes o direito a comunicação recebeu destaque durante o processo, como se observa na análise qualitativa.

No mês de abril de 1987 o deputado Vladimir Palmeira (PT/RJ) profere discurso alegando que a liberdade de expressão somente é assegurada na sua plenitude se houver uma verdadeira "democratização dos meios de comunicação", não sendo possível, desta forma, tolerar-se o monopólio na propriedade dos meios, tornando-se esse um instrumento de poder. (SEEP, 2008, p. 178/179).

No mesmo sentido, o deputado Airton Cordeiro (PDT/PR) se manifesta acerca da futura regulação dos meios de comunicação social, compreendendo ser este um dos mais sensíveis e polêmicos assuntos a serem tratados no futuro texto constitucional, pois "a concessão dos direitos de exploração dos canais de rádio e televisão se transformou, através dos anos, em instrumento poderoso de ação política, em instrumento cerceador da voz daqueles compromissados com os princípios democráticos do País", bem como o uso das emissoras de rádio e televisão podem transformar-se em instrumentos de doutrinação, verdadeira catequese ideológica e, por isso, "a concessão de emissoras de rádio e televisão não pode ser um trampolim pura e simplesmente para objetivos políticos, não pode ser o cerceamento do direito à opinião, à livre manifestação de todos os cidadãos deste País". (SEEP, 2008, p. 214/215)

Em maio de 1987 o constituinte Gonzaga Patriota (PMDB/PE), retoma a temática em plenário, alegando que o direito de comunicação deve ser livre e garantido a todos os brasileiros, no entanto, propõe restrições à propaganda de remédios, fumo e bebidas alcoólicas, bem como sugere a definição de "um percentual mínimo de programas culturais, musicais e educativos nos meios de comunicação". Ademais, propõe a possibilidade de lei estabelecer "formas de controle da sociedade civil sobre os meios de comunicação", sugere ainda a revogação de leis, dentre outras, da lei de imprensa. No entanto, discursa o constituinte que

para a construção de uma sociedade democrática, se faz mister que se assegure, amplamente, a liberdade dos meios de comunicação social, e acreditamos que será mantida a tradição existente desde a Carta Política de 1824, que proclamou a liberdade de imprensa. $\mathrm{O}$ direito social da comunicação não pode servir para a 
criação de monopólios da informação e do controle da opinião pública nacional por grupos econômicos, devendo, por isso mesmo, a União adotar critérios mais adequados à defesa do povo, quando da concessão pública de canais de rádio e de TV (SEEP, 2008, p.128-131)

O deputado Sólon Borges dos Reis $(\mathrm{PTB} / \mathrm{SP})$ afirma em plenário que não há democracia sem imprensa livre, pois "a opinião pública se constitui e se consolida com a informação e a imprensa concorre para sua formação e deve ser sua intérprete. E a opinião pública é instituição essencial ao regime democrático", defende "a abolição de toda e qualquer censura à imprensa, que deve ter liberdade irrestrita", mas relembra que não há liberdade de imprensa irresponsável e que "a irresponsabilidade nos meios de comunicação não pode merecer a solidariedade de ninguém”. (SEEP, 2008, p. 284).

Ainda no mês de maio, o constituinte Jorge Vianna (PMDB/BA), pronuncia extenso discurso, sugerindo, dentre inúmeras outras propostas, que a nação brasileira, através da nova constituição, deve definir "com clareza a natureza nacional de seus meios de comunicação de massa, suas finalidades sociais, seus limites e suas responsabilidades sociais, dando ao povo a competência para propor a cassação de concessões, quando fugindo ao que por ele foi definido". (SEEP, 2008, p. 318/320) p. $73 / 74)^{12}$

Vladimir Palmeira (PT/ RJ) retorna à tribuna, em junho, afirmando que (SEEP, 2008,

A cabeça do País passa hoje pela TV e pelo rádio, em particular, pela primeira. O antigo preceito de liberdade de expressão não tem, hoje, sentido se não há acesso aos meios de comunicação de massa. Já foi o tempo em que ser livre era dizer o

\footnotetext{
12 Também propõe algumas ideias inovadoras, mas que, no entanto, não surtiram efeitos na redação final: "Defendermos a criação de um Conselho Comunitário de Comunicação, que traçará a política de telecomunicações e concederá os canais de radio e TV, ad referendum do Congresso Nacional. Este conselho deverá ser composto por representantes do Estado e da sociedade civil: partidos, centrais sindicais, centrais de moradores, representantes sindicais dos jornalistas e dos empresários do setor, representantes dos sindicatos de artistas. Será proibido a qualquer pessoa, física ou jurídica, ter mais de uma emissora de TV, ou ter participação acionaria em outra empresa. Não poderá cada emissora emitir mais que para seu próprio Estado, sendo autorizada rede nacional, em um máximo de duas horas diárias. A reposição de programas de outro Estado se limitará a $10 \%$ da programação. Vinte por cento, pelo menos da programação de cada emissora serão produzidos no próprio Estado. Tudo isto evita a pasteurização cultural e preserva a diversidade regional. As emissoras só poderão produzir até cinqüenta por cento de sua programação, abrindo espaço para produção independente e ampliando o mercado de trabalho. O Conselho Comunitário Nacional disciplinará o acesso ao rádio e TV locais, reservando esta faixa para a comunidade. Um fundo nacional será criado para estimular a rádio e a TV comunitárias, extraído da receita bruta de propaganda das emissoras comerciais. Partidos políticos, centrais sindicais e de moradores terão um mínimo de quatro horas anuais nas emissoras comerciais para colocar suas propostas e expor seu trabalho. Sem democratização dos meios de comunicação, não há liberdade. (SEEP, 2008, p. 73/74).
} 
que quiséssemos no botequim da esquina, ou em reunião seleta. Hoje, qualquer manifestação toca uma parte pequena da população, salvo se divulgada pela TV. E esta é, sem si, um instrumento poderoso de cultura, política e ideologia. Não queremos estes poderosos meios de comunicação nas mãos do Estado. Mas também não os queremos em mãos monopólicas de qualquer espécie, singulares ou globais.

Antonio Mariz (PMDB/PB) defende a definição de diretrizes para o uso dos meios de comunicação, a regulação jurídica para proibição de monopólios ou oligopólios na área, bem como regras que assegurem "aos partidos e às entidades representativas da sociedade o acesso à comunicação”. (SEEP, 2008, p. 395/397).

O deputado carioca Carlos Alberto Caó (PDT), um dos constituintes que mais atuaram em prol da regulação do direito à comunicação, sendo inclusive dele a proposta originária de proibição de monopólio e oligopólio sobre a propriedade dos meios, profere discurso em junho de 1997, alegando que os meios de comunicação de massa "constituem uma poderosa arma política. E se eles são utilizados simplesmente pela lógica dos interesses econômicos privados de arma política, poderão atribuir aos seus titulares, aos seus donos, a posição de atores políticos que pretenderam até substituir o papel que os partidos políticos exercem na democracia" e reconhecendo que no mundo moderno "a comunicação se tomou um direito fundamental da pessoa humana, e a informação um bem da sociedade", conclui que "o acesso aos meios de informação é hoje, sem dúvida, não só uma das faces do exercício da liberdade de imprensa, como parte constitutiva da cidadania, dentro da dinâmica do Estado e sociedades democráticas", diante disso, propõe juntamente com seu partido que:

1) Aos meios de comunicação devem ser atribuídos o papel de atuar a serviço da verdade, da eliminação das desigualdades e injustiças sociais, da independência econômica, política e cultural do povo brasileiro. 2) A base dessa atuação deve residir no pluralismo ideológico. A pluralidade de opiniões, idéias, visões e concepções do mundo deve presidir a transmissão e divulgação de informações. Essa destinação torna-se, portanto, incompatível com centralização e concentração dos meios de comunicação de massa. 3) Impõe-se, dessa forma, que os meios de comunicação e serviços relacionados com a liberdade de expressão não podem, direta ou indiretamente, ser objeto de monopólio, oligopólio, por parte de empresas privadas ou públicas. 4) É preciso, no entanto, sob pena de pôr em risco a segurança e a soberania do Estado-Nação brasileiro, que a nova Constituição expressamente estabeleça que constitui monopólio da União a exploração de serviços públicos de telecomunicações, comunicação postal, telegráfica e de dados. 5) Independe de licença da autoridade a publicação de veículo impresso, assim 
como a lei não poderá restringir a liberdade de imprensa exercida por qualquer meio de comunicação. É preciso, no tanto, para assegurar a liberdade de informação, que o direito de resposta seja respeitado. Que a transgressão ao direito de resposta implique na definição de responsabilidades penais, na forma que a lei determinar. 6) Sabidamente, a atual estrutura do sistema de radiodifusão (canais de rádio e de televisão) engendra graves violações às liberdades democráticas, aos direitos civis e à cidadania, transgredindo, com regularidade, a liberdade de informação. Profundas transformações se impõem para que a democratização se concretize: a) A começar pelo processo decisório na outorga e concessão de canais de rádio e televisão, atualmente confiada à decisão solitária do Chefe do Poder Executivo. A distribuição de canais influencia de tal sorte a informação de idéias e deforma manifestações culturais, que se tomou uma imposição da democratização do próprio Estado que a sociedade civil intervenha na formação das decisões, através da instituição do Conselho Nacional de Comunicações. b) ao Conselho Nacional de Comunicação seriam reservadas as competências de elaborar uma política nacional de comunicação e outorgar, conceder, autorizar e renovar, ad referendum do Congresso Nacional, concessões de rádio e televisão. De fato e de direito, o Conselho representa simultaneamente o papel de um órgão auxiliar do Poder Legislativo e, pela sua composição a ser definida pelo Congresso, expressaria os interesses da sociedade civil. c) Na elaboração da política nacional de comunicação que se submeteria ao Congresso Nacional, reconhece-se como essencial que o Conselho trace diretrizes capazes de transformarem - ao contrário do que hoje se verifica - canais de rádio e televisão em instrumentos de promoção da cultura brasileira e das culturas regionais. (SEEP, 2008, p. 609/610).

O deputado constituinte paulista Geraldo Alckmin Filho (PMDB), em agosto de 1987, profere discurso no plenário defendendo "que a informação constitui base essencial para o progresso da civilização e das sociedades, constituindo, como observou, com propriedade, a UNESCO, em recente obra sobre o assunto, um elemento chave para a tomada de decisões políticas." Diante disso, reconhece "a importância dos meios de comunicação no contexto da vida contemporânea, seja como cenário capaz de fazer florescer a semente da liberdade, seja como fator de renovação espiritual e social das diversas comunidades" e aduz que por esta razão a regulação das concessões de emissoras de rádio e TV tornou-se, naquele momento histórico, um tema polêmico que gerou mais conflitos do que as propostas de reforma agrária, por exemplo. (SEEP, 2008, p. 162-163).

Até o final de 1987 os trabalhos do plenário, como já dito anteriormente, ocorriam simultaneamente aos trabalhos desenvolvidos pelas subcomissões, comissões temáticas e pela comissão de sistematização. Cumpre ressaltar que nas fases anteriores a do plenário, em relação à regulação do direito à comunicação nada foi decidido, sendo as votações nessas fases polarizadas entre progressistas e conservadores, saindo vencedores estes últimos, sem 
que houvesse aprovação de qualquer proposta ou encaminhamento de proposta de texto a ser deliberado em plenário ${ }^{13}$.

Em 1988 o plenário da ANC voltou a se reunir agora também para deliberar sobre a proposta oriunda da comissão de sistematização. ${ }^{14}$ Nesta fase, diferentemente das anteriores houve deliberações.

Em fevereiro de 88, o deputado gaúcho Mendes Ribeiro (PMDB) pronuncia discurso para defender proposta de sua autoria sobre a proibição do anonimato nas manifestações do pensamento, alegando que deve haver uma "bendita mistura" entre liberdade e responsabilidade, inexistindo a primeira sem a segunda, pois se não fosse assim "assistiríamos

${ }^{13}$ Conforme fala em plenário do deputado Carlos Alberto Caó em março de 88 (SEEP, 2008, p. 199/201). "Sr.
Presidente, nobres Constituintes, dentro de algumas semanas, a Assembléia Nacional Constituinte será chamada
a adotar decisões de fundamental importância para a construção do Estado democrático, ao discutir o capítulo
das Comunicações no Projeto da Comissão de Sistematização. Esse tema - pleno de aspectos polêmicos - não
tem sido realmente votado nas diversas fases do processo constituinte - desde as Subcomissões até à Comissão
de Sistematização, onde por decurso de prazo deixou de ser votado".
${ }^{14}$ Era a seguinte proposta encaminhada pela comissão de sistematização para ser apreciada pelo plenário: "DA ${ }^{14}$ Era a seguinte proposta encaminhada pela comissão de sistematização para ser apreciada pelo plenário: "DA
COMUNICAÇ̃̃ O - Art. 249 - É assegurada aos meios de comunicação ampla liberdade, nos termos da lei. § $1^{\circ}$ - É vedada toda censura de natureza política e ideológica. A lei criará os instrumentos necessários para defender a pessoa: I - da exibição, e veiculação de programas e mensagens comerciais, do rádio e da televisão, que utilizem temas ou imagens que atentem contra a moral, os bons costumes, e incitem à violência; II - da propaganda comercial de bens e serviços que possam ser nocivos à saúde. $\S 2^{\circ}-$ Os meios de comunicação não podem, direta ou indiretamente, ser objeto de monopólio ou oligopólio, público ou privado. $\S 3^{\circ}-\mathrm{A}$ publicação de veículo impresso de comunicação não depende de licença de autoridade. $\S 4^{\circ}$ - É assegurada a prestação de serviços de transmissão de informações por entidades de direito privado, através de rede pública. Art. 250 - As emissoras de rádio e televisão promoverão o desenvolvimento integral da pessoa e da sociedade, observados os seguintes princípios: I - preferência às finalidades educativas, artísticas, culturais e informativas; II - promoção da cultura nacional e da regional, e preferência à regionalização da produção cultural e artística; III complementariedade dos sistemas público, privado e estatal; Art. 251 - A propriedade das empresas jornalísticas e de radiodifusão é privativa de brasileiros natos ou naturalizados há mais de dez anos, aos quais caberá a responsabilidade principal pela sua administração e orientação Intelectual. $\S 1^{\circ}-$ É vedada a participação acionária de pessoas jurídicas no capital social de empresas jornalística ou de radiodifusão, exceto a de partidos políticos e de sociedades de capital exclusivamente nacional. $\S 2^{\circ}-$ A participação referida no parágrafo anterior, que só se efetivará através de ações sem direito a voto e não conversíveis, não poderá exceder a trinta por cento do capital social. Art. 252 - Compete ao Poder Executivo outorgar e renovar concessão, permissão e autorização para o serviço de radiodifusão sonora e de sons e imagens. $\S 1^{\circ}$ - Compete ao Congresso Nacional apreciar o ato, em regime de urgência, a partir de sua publicação, no prazo do $\S 4^{\circ}$ do artigo 74 . $\S 2^{\circ}$ - A não renovação da concessão ou permissão dependerá da manifestação expressa da maioria absoluta do Congresso Nacional. $\S 3^{\circ}-$ $\mathrm{O}$ cancelamento da concessão ou permissão, antes de vencido o prazo depende de decisão judicial. $\S 4^{\circ}-\mathrm{O}$ prazo da concessão e da permissão será de dez anos para as emissoras de rádio e de quinze anos para as emissoras de televisão. Art. 253 - Para os efeitos do disposto neste capitulo, o Congresso Nacional instituirá, na forma da lei, como seu órgão auxiliar, o Conselho Nacional de Comunicação, com participação paritária de representantes indicados pelo Poder Legislativo e pelo Poder Executivo. Art. 254 - A lei incentivará medidas que levem à adaptação progressiva do rádio e da televisão, a fim de permitir que as pessoas portadoras de deficiência sensorial tenham acesso á informação e à comunicação." Observe-se que à despeito de algumas diferenças na redação final do texto constitucional e do quorum para a não renovação, a maioria dessas propostas foram aprovadas em plenário, a exceção das que estão sublinhadas. 
ao reinado da anarquia". A necessidade de identificação da autoria tem, segundo o seu propositor, a intenção de fixação das responsabilidades pela divulgação de fatos inverídicos, desairosos, sem fundamento, por isso, a necessidade de "identificação do responsável pela informação". (SEEP, 2008, p.15).

$\mathrm{Na}$ sequência dos trabalhos do plenário, em março, o constituinte Pompeu de Sousa $(\mathrm{PMDB} / \mathrm{DF})$ sobe à tribuna do Congresso Nacional para convocar a ANC a adotar para a liberdade de imprensa e para a liberdade de informação pública o status de cláusula pétrea, tal como estava sendo previsto e foi confirmado para a forma federativa do Estado, o voto direto, secreto, universal e periódico, a separação dos poderes e os direitos e garantias individuais, pois segundo o constituinte esses direitos "transcendem em multo o âmbito das liberdades e garantias individuais, porque representam a própria liberdade e garantia da comunidade nacional. A liberdade de imprensa não é apenas um direito do jornalista e do veículo de informação; a liberdade de informação pública também não é apenas um direito de veículo de informação pública, elas são uma obrigação, porque se constituem um direito da Nação e do povo brasileiro". (SEEP, 2008, p. 249).

O deputado Carlos Alberto Caó (SEEP, 2008, p. 199/201) discursa atribuindo um papel de vital importância aos meios de comunicação de massa, para o fortalecimento e consolidação da convivência democrática. Para o constituinte "nos Estados democráticos, através de medidas legais, disposições constitucionais e mecanismos institucionais, tem-se imposto a diretriz de - mantida em toda a linha da liberdade de expressão - estabelecer a vinculação/subordinação dos meios de comunicação de massa (radiodifusão, em especial) à sociedade civil." Faz referência a Duverger que reconhece a força política dos meios e para quem a pluralidade desses é condição para a pluralidade do próprio regime político e, segundo o deputado, a democratização dos meios é um imperativo histórico para a consolidação da democracia e para o fim da experiência autoritária no Estado brasileiro.

O deputado Artur da Távola (PMDB - RJ), que tinha exercido a função de relator na comissão temática que tratou da comunicação social, propôs, em março/88, emenda ao texto encaminhado pela comissão de sistematização para incluir na redação final da constituição regra proibitiva para os parlamentares receber concessões de rádio e $\mathrm{TV}$, pois como uma concessão necessariamente deve ser aprovada pelo Congresso esse fato, por si só, pode ser 
gerador de corrupção, segundo o constituinte a

\begin{abstract}
proposta é saneadora, no sentido de preservar o Congresso e seus membros da sedução de usar o poder em proveito próprio. Jamais optaremos com liberdade, eqüidistância e justiça se formos parte interessada na decisão. A medida que ora proponho não possui caráter moralista no sentido restrito do termo. Filia-se, sim, a altos propósitos éticos ao preservar a incolumidade do Parlamento no momento de decidir sobre matéria tão grave e profunda. Hoje, a penetração e o efeito dos meios de comunicação na sociedade impõem revisão completa das finalidades e formas de uso de quem os comanda. Só poderemos nos atribuir o poder de decidir se ele jamais servir a beneficiar-nos. Não podemos arrojar-nos à posição de árbitros se nos transformarmos em partes interessadas. (SEEP, 2008, p. 211).
\end{abstract}

No dia 07 de abril, dia dos jornalistas, o constituinte Edmilson Valentim (PC do B/RJ) (SEEP, 2008, p. 234/235) usa a tribunal para, além de homenagear esses profissionais, incitar os colegas a aprovarem o texto constitucional, com mudanças objetivas para o campo da liberdade de imprensa que viabilizem o "conceito da informação como um bem social".

Farabulini Júnior (PTB/SP) (SEEP, 2008, p. 95/96) apresenta em plenário um manifesto do intitulado "Movimento pela Defesa da Cultura"15, para quem as emissoras de rádio e TV deveriam constituir-se em um bem social e as concessões e utilizações desses canais de comunicação deveriam "estar subordinados aos interesses e necessidades da comunidade". De acordo com o manifesto "a atual filosofia da rede de radiodifusão concentra quase que totalmente a produção em um único pólo gerador, desempregando milhares de profissionais de todas as áreas, favorecendo a manifestação de informações e descaracterizando culturalmente o País". O movimento defende a obrigatoriedade da regionalização da produção cultural e artística nas emissoras de rádio e televisão, pois "os meios de comunicação não podem, diretamente ou indiretamente, ser instrumento de monopólio ou oligopólio, público ou privado", sendo certo que "a democratização dos meios

\footnotetext{
${ }^{15}$ Compunham o MOVIMENTO PELA DEFESA DA CULTURA as seguintes entidades: Sindicato dos Artistas e Técnicos em Espetáculos de Diversões no Estado de São Paulo - SATED/SP. - União Brasileira dos Escritores - UBE - Federação Paulista de Cineclubes - FPCc - Cooperativa Paulista de Teatro - CPT - Associação dos Produtores Espetáculos Teatrais do Estado de São Paulo - APETE - Sindicato dos Jornalistas Profissionais do Estado de São Paulo - Associação Paulista dos Autores Teatrais - APART - União dos Fotógrafos do Estado de São Paulo - Associação Paulista dos Críticos de Arte - APCA - Associação Brasileira dos Críticos de Arte ABCA Associação Ecológica Fiscais da Natureza - Sindicato dos Escritores no Estado de São Paulo - Sindicato dos Trabalhadores na Indústria Cinematográfica - Associação Paulista de Cineastas (APACI) - Associação Profissional dos Artistas Plásticos - Associação Brasileira de Imprensa (ABI) - Movimento Nacional pela Democratização da Comunicação.
} 
de comunicação social deve ser garantida por esta Constituição". Para os representantes do movimento "o desenvolvimento cultural do Brasil implica no livre acesso à informação e aos meios necessários à criação, produção e apropriação dos bens culturais" e "no reconhecimento e respeito às especificações culturais dos múltiplos universos e modos de vida da sociedade brasileira, e na preservação e ampliação da função predominantemente cultural dos meios de comunicação social e seu uso democrático". Diante disso, propõe o movimento que:

as rádios e televisões sejam obrigadas legalmente a ter no mínimo $70 \%$ de sua programação feita no Brasil, com um percentual gerado regionalmente que deverá ser definido em lei. A produção regional deve ser equitativamente distribuída pelos diversos horários, garantindo-se a regionalização da produção artística, conceituada diferentemente do setor educativo ou propagandístico, ampliando, assim, o mercado de trabalho. Os atores, autores, diretores e técnicos brasileiros devem ter assegurado legalmente o direito de trabalhar no seu estado de origem. Além disso, o fundamental é que, uma vez implantadas, estas medidas garantirão a auto-expressão da sociedade brasileira; seja garantida a utilização gratuita do rádio e da televisão às entidades sindicais e organizações populares. Sendo estabelecidas constitucionalmente a liberdade de manifestação, de pensamento e de concepções político-religiosas, é imprescindível que os meios de comunicação tenham seu uso democratizado e socializado (acréscimo ao art. 256).

Em maio de 88 o presidente da ANC, deputado Ulysses Guimarães coloca em votação o texto constitucional sobre a comunicação social. A redação foi uma proposta do Centrão e incorporava várias fusões de emendas ${ }^{16}$. A proposta foi aprovada com 415 votos a

\footnotetext{
${ }^{16}$ Proposta do Centrão: Da Comunicação: Art. 251. É assegurada aos meios de comunicação ampla liberdade, nos termos da lei. $\S 1^{\circ}$ É vedada a censura de natureza política e ideológica. A lei criará os instrumentos necessários para defender a pessoa humana: I - da exibição e veiculação de programas e mensagens comerciais, no rádio e na televisão, que utilizem temas ou Imagens que atentem contra a moral, os bons costumes e incitem à violência. II - da propaganda comercial de produtos, práticas e serviços que possam ser nocivos à saúde. $\S 2^{\circ} \mathrm{Os}$ meios de comunicação de massa não podem, direta ou indiretamente, ser objeto de monopólio ou oligopólio, público ou privado. $\S 3^{\circ} \mathrm{A}$ publicação de veículo impresso de comunicação não depende de licença de autoridade. Art. 252. As emissoras de rádio e de televisão, resguardado o dever de bem informar, cooperarão para o aprimoramento da sociedade, mediante a valorização de suas finalidades educativas, artísticas, culturais e promocionais dos valores humanos, levando sempre em conta, na sua programação, as peculiaridades regionais do País. Art. 253. A propriedade de empresas jornalísticas e de radiodifusão é privativa de brasileiros natos ou naturalizados há mais de dez anos, a sua administração e orientação intelectual. $\S 1^{\circ}$ É vedada a participação acionária de pessoa jurídica no capital social de empresa jornalística ou de radiodifusão, exceto a de partidos políticos e de sociedades de capital exclusivamente nacional. $\S 2^{\circ} \mathrm{A}$ participação referida no parágrafo anterior, que só se efetivará através de ações não conversíveis e sem direito a voto, não poderá exceder a trinta por cento do capital social. Art. 254. Compete ao Poder Executivo outorgar e renovar concessão, permissão e autorização
} 
favor, 10 contra e duas abstenções.

Ainda no mês de maio, nova proposta sobre a regulação da comunicação social foi colocada em votação pelo presidente da ANC (SEEP, 2008, p. 589), desta vez, oriunda de um amplo acordo entre os constituintes. A nova proposta foi aprovada ${ }^{17}$ com 443 votos a favor, 8 contra e sete abstenções.

A proposta aprovada em Primeiro Turno, no que diz respeito à comunicação social, originou-se, segundo Pilatti (2008, p. 274), de um acordo partidário, subscrito por 50

para o serviço de radiodifusão sonora e de sons e imagens. $\S 1^{\circ}$ Compete ao Congresso Nacional apreciar o ato de outorga, no prazo do artigo 78 , parágrafo $4^{\circ} \S 2^{\circ}$ A não renovação da concessão ou permissão dependerá de manifestação expressa da maioria absoluta do Congresso Nacional. $\S 3^{\circ} \mathrm{O}$ cancelamento da concessão ou permissão, antes de vencido o prazo, depende de decisão judicial. $\S 4^{\circ} \mathrm{O}$ prazo da concessão ou permissão será de dez anos para as emissoras de rádio e de quinze anos para as emissoras de televisão. Art. 255. Para os efeitos do disposto neste Capítulo, o Congresso Nacional instituirá, na forma da lei, como órgão auxiliar, o Conselho Nacional de Comunicação, com participação partidária de representantes indicados pelo Poder Legislativo e pelo Poder Executivo. Art. 256. A lei incentivará medidas que levem à adaptação progressiva dos meios de comunicação, a fim de permitir que pessoas portadoras de deficiências tenham acesso à informação.

${ }^{17}$ Proposta do acordo: Da Comunicação: Art. 251. A manifestação do pensamento, da criação e expressão, bem como a informação, sob qualquer forma, processo ou veiculação, não sofrerão qualquer restrição, observado o disposto nesta Constituição. $\S 1^{\circ}$ Nenhuma lei conterá dispositivo que possa constituir embaraço à plena liberdade de informação jornalística em qualquer veículo de comunicação social, observado o disposto no art. $6^{\circ}, \S \S 5^{\circ}$ e $10 . \S 2^{\circ}$ É vedada toda e qualquer censura de natureza política, ideológica e artística. Compete à lei federal: I - regular as diversões e espetáculos públicos, cabendo ao Poder Público informar sobre a natureza dos mesmos e as faixas etárias, locais e horários nos quais sua apresentação se mostre inadequada; II - estabelecer os meios legais que garantam à pessoa e à família a possibilidade de se defenderem de programas ou programações de rádio e televisão que contrariem o disposto no art. 252 e incisos, bem como da propaganda de produtos, práticas e serviços que possam ser nocivos à saúde e ao meio ambiente. $\S 3^{\circ}$ Os meios de comunicação social não pode, direta ou indiretamente, ser objeto de monopólio ou oligopólio. $\S 4^{\circ} \mathrm{A}$ publicação de veículo impresso de comunicação independe de licença de autoridade. Art. 252. A produção e a programação das emissoras de rádio e televisão atenderão aos seguintes princípios: I - preferência por finalidades educativas, artísticas, culturais e informativas; II - promoção da cultura nacional e regional e estimulo à produção independente que objetive a sua divulgação; III - regionalização da produção cultural e artística, conforme percentuais estabelecidos em lei; IV - respeito aos valores éticos e sociais da pessoa e da família. Art. 253. A propriedade de empresas jornalísticas e de radiodifusão é privativa de brasileiros natos ou naturalizados há mais de dez anos, aos quais caberá a responsabilidade pela sua administração e orientação intelectual. $\S 1^{\circ}$ É vedada a participação de pessoa jurídica no capital social de empresa jornalística ou de radiodifusão, exceto a de partidos políticos e de sociedade cujo capital pertença exclusiva e nominalmente a brasileiros.

$\S 2^{\circ}$ A participação referida no parágrafo anterior só se efetuará através de capital sem direito a voto e não poderá exceder a trinta por cento do capital social. Art. 254. Compete ao Poder Executivo outorgar e renovar concessão, permissão e autorização para o serviço de radiodifusão sonora e de sons e imagens, observado o princípio da complementariedade dos sistemas privado, público e estatal. $\S 1^{\circ}$ Compete ao Congresso Nacional apreciar o ato, em regime de urgência, a partir do recebimento da mensagem, no prazo do art $78, \S \S 2^{\circ}$ e $4^{\circ}$. $\S 2^{\circ}$ A não renovação da concessão ou permissão dependerá da manifestação de dois quintos do Congresso Nacional em votação nominal. $\S 3^{\circ} \mathrm{O}$ ato de outorga ou renovação somente produzirá efeitos legais após deliberação do Congresso Nacional, na forma dos $\S \S 1^{\circ}$ e $2^{\circ}$ deste artigo. $\S 4^{\circ} \mathrm{O}$ cancelamento da concessão ou permissão, antes de vencido o prazo, depende de decisão judicial. $\S 5^{\circ} \mathrm{O}$ prazo de concessão ou permissão será de dez anos para as emissoras de rádio e de quinze anos para as emissoras de televisão. Art. 255. Para os efeitos do disposto neste capítulo, o Congresso Nacional instituirá como órgão auxiliar, o Conselho de Comunicação Social, na forma da lei. 
constituintes de todos os partidos e "apresentava as seguintes diferenças em face do texto do Centrão: previa a complementaridade dos sistemas privado, público e estatal de comunicação; reduzia de maioria absoluta para dois quintos o quórum necessário para não-renovação de concessão de rádio ou TV pelo Congresso, e estendia o mesmo quórum às decisões sobre outorga e renovação de concessões; eliminava a previsão de composição paritária Executivo/Legislativo para o Conselho Nacional de Comunicação"

Ainda segundo Pilatti (2008, p. 274) "com o acordo, pela primeira vez uma constituição brasileira teria, como pretendiam os progressistas, um capítulo sobre comunicação social que, embora estabelecesse o controle do Congresso Nacional sobre as concessões de rádio e televisão, tinha seu conteúdo geral mais próximo das preferências dos conservadores". ${ }^{18}$

O início das votações no plenário foi caracterizado por forte tensão entre os constituintes. Essa tensão fez com que as primeiras votações continuassem no impasse, mas os constituintes logo perceberam que para conseguir a maioria suficiente para aprovação do texto era necessário estabelecer acordos. Com isso as votações começaram a fluir.

De acordo com Pilatti ( 2008, p. 272)

Ao contrário do que acontecera em todas as fases anteriores com os temas relativos aos Capítulos IV (Ciência e Tecnologia) e V (Comunicação) do Título VIII, a votação em Plenário das respectivas emendas substitutivas apresentadas pelo Centrão foi marcada pelo entendimento [...]. A rigor, sobre esses temas o entendimento tinha se iniciado com a votação do monopólio das telecomunicações, no Título II.

Graças a esse acordo, pela primeira vez uma constituição brasileira teria um capítulo sobre comunicação social. Esse capítulo agregaria várias questões discutidas e apresentadas desde a subcomissão de Ciência e Tecnologia e da Comunicação, mas ao mesmo tempo em diversos pontos o texto aprovado não se deu nos termos desejados nas etapas anteriores.

Essas observações ilustram que enquanto o assunto da regulação da comunicação estava nos pequenos foros da subcomissão e da comissão temática a oposição, amparada por ${ }^{18}$ Couto (1998), ao analisar o processo constituinte, informa que durante os trabalhos não houve na Assembleia
Nacional Constituinte uma coalizão parlamentar que pudesse impor suas ideias, havendo um processo de
barganhas para a aprovação de alguns temas constitucionais.
268 
entidades representativas da sociedade, teve forças para levar a discussão adiante, mas no plenário, contudo, os interesses dos majoritários parlamentares concessionários ou aliados de concessionários de emissoras de rádio e TV fizeram impor sua vontade. (JAMBEIRO, 2009).

De acordo com Jambeiro (1999, p. 133/134), em trabalho que analisa a regulação da comunicação social nas constituições brasileiras do século XX, a constituição de 1988, se comparada às anteriores, no que se refere à comunicação social, "apresenta alterações substanciais relativas a este setor econômico-cultural", no entanto, "expressam mais fortemente o pensamento conservador" do que propriamente vitórias sociais democratas".

Vicente (1999, p. 156), em texto que põe em xeque a regulação pós constitucional da comunicação social, tem a mesma compreensão sobre a constituição de 88 , pois

houve um cuidado especial em formular com nitidez direitos e garantias para a liberdade de expressão e informação. Em tese, esse princípio norteador significou um avanço substancial se comparado com a censura e falta de garantias de informação ocasionadas pelos Atos Institucionais adotados no regime autoritário.

Vicente (1999, p. 156/157) conclui que "resulta difícil não aceitar e perceber os avanços provenientes da Constituição de 1988 na área da Comunicação".

\section{CONCLUSÕES}

Pelo que foi exposto, pode-se preliminarmente, até mesmo pelo fato do presente texto tratar-se de resultado parcial de pesquisa, concluir que durante os trabalhos do plenário da ANC havia uma orientação no sentido de compreender os meios de comunicação como instrumentos essenciais para a democracia e para a construção da cidadania, reconhecendo-se que os meios são poderosos instrumentos de poder político e por isso essas atividades econômicas necessitariam de regulação jurídica.

A regulação estaria centrada, em apertada síntese, segundo as propostas parlamentares: na proibição do monopólio/oligopólio da propriedade dos meios; na restrição a algumas formas de publicidade e propaganda; na previsão das suas responsabilidades sociais; na subordinação dessas atividades aos interesses da sociedade, propondo-se formas de controle social sobre a atividade dos meios e regras que garantissem o acesso aos meios de 
comunicação por entidades representativas da sociedade civil, através do direito de antena.

Propunha-se também a definição de regras jurídicas para garantir a regionalização da produção cultura, reconhecendo-se a importância dos meios como instrumento para a difusão desse bem imaterial.

Extrai-se também que era voz comum no plenário que a comunicação deveria ser reconhecida como um direito fundamental e um bem social e por essa razão as liberdades relacionadas à comunicação deveriam ser dosadas com responsabilidades, relativizando-se aquelas.

Conclui-se que a grande maioria das propostas foram adotadas pela ANC, no entanto, algumas deixaram de ser, como exemplos: a ampliação do direito de antena, hoje restrito aos partidos políticos; regras que garantam o controle social dos meios; não reconhecimento expresso dos direitos relacionados à comunicação como bens sociais.

Por fim, reconhece a pesquisa que no plano da realidade várias regras jurídicas previstas no texto constitucional aprovado pelo plenário da $\mathrm{ANC}$ ainda não foram concretizadas, como exemplos: as regras proibitivas da monopolização / oligopolização do setor; a regionalização da produção cultural, representando essas práticas uma afronta ao desejo manifestado pela ANC e conhecido expressamente no texto da constituição de 1.988.

\section{BIBLIOGRAFIA}

AGUILLAR, F. H. Direito econômico. São Paulo: Atlas, 2006.

BONAVIDES, P. Curso de direito constitucional. 10 Ed. São Paulo: Malheiros, 2000.

BRANT, J.; KAMEOKA, M. (Coord.). Direito à comunicação no Brasil. Disponível em: < ww.scribd.com/doc/5619429/Direito-a-comunicacao-no-Brasil-Intervozes>. Acesso em: várias datas, 2005.

COUTO, C. G. A longa constituinte: reforma do Estado e fluidez institucional no Brasil. Dados, v. 41, n. 1, 1998, pp. 51/86.

GONÇALVES, M. E. Direito da informação: novos direitos e formas de regulação na sociedade da informação. Coimbra: Almedina, 2003. 
JAMBEIRO, O. A comunicação na Constituição de 1988. In: GOULART, J. O. As múltiplas faces da constituição cidadã. São Paulo: Cultura Acadêmica, 2009.

PILATTI, A. A Constituinte de 1987-1988: Progressistas, Conservadores, Ordem Econômica e Regras do Jogo. Rio de Janeiro: Lúmen Júris, 2008.

SECRETARIA ESPECIAL DE EDITORAÇÃO E PUBLICAÇÕES. Secretaria de Anais. Assembleia Nacional Constituinte - 20 anos: Atas do Plenário da Assembleia Nacional Constituinte. Brasília, 2008.

SCHÄFER, J. G. Direitos fundamentais, proteção e restrições. Porto Alegre: Livraria do Advogado Editora, 2001.

VICENTE, M. M. Comunicação em xeque: o debate na regulamentação pós-constituição. In: GOULART, J. O. As múltiplas faces da constituição cidadã. São Paulo: Cultura Acadêmica, 2009 .

Enviado em: 07/11/2012

Aprovado em: 20/11/2013

Sobre o autor: Carlo José Napolitano

Doutor em Direito e é professor da Faculdade de Arquitetura, Artes e Comunicação da Unesp. 